\title{
Investigating The Neglected Safety Practices Influencing Safety Performance Of Building Construction Projects In Sindh Province Of Pakistan
}

\author{
Muhammad Tarique, LAKHIAR \\ Faculty of Civil Engineering and Built Environment, UTHM, Parit Raja, Johor, Malaysia \\ hf190023@siswa.uthm.edu.my \\ Abd Halid, ABDULLAH \\ Faculty of Civil Engineering and Built Environment, UTHM, Parit Raja, Johor, Malaysia \\ hf190023@siswa.uthm.edu.my \\ Muhammad Tahir, LAKHIAR \\ Department of Civil Engineering, Monash University, Subang Jaya, Selangor Malaysia \\ hf190023@siswa.uthm.edu.my
}

\begin{abstract}
Safety non-performance has not only contributed to higher levels of injuries but also decreased total productivity in the building sector. Through improving standards of safety practices, the condition can be changed. This paper provides a framework for recognizing the most neglected safety practices that must be improved. The research was performed using a questionnaire survey of 33 safety practices. Data obtained through 210 questionnaires from respondents who were working on building projects in the Sindh Province were analyzed using statistical package for the social sciences. All safety practices have been prioritized based on their mean safety performance values. Statistics have shown that the average safety performance of the building industry is 60.596 per cent. Construction safety practices that need special attention are listed as; (a) People should work safely even when they are not being supervised (b) Safety training provided to the employees of subcontractors (c) Investigations carried out to identify the causes of accidents (d) Accidents are reported/recorded (e) throwing or dropping of material/equipment carelessly. The findings also have shown that the factor 'Accident reporting and investigation mechanism', has the lowest level of safety performance, accompanied by 'Workers' involvement', 'Safety training', 'Safety practices', 'Safety meetings. The findings of this report will provide building stakeholders with valuable knowledge for safe work practices.
\end{abstract}

\section{Keywords}

Safety Practices, Pakistan Engineering Council, Safety Performance

\section{Introduction}

The building sector plays a vital position in both eastern and western economies, responsible for about $10 \%$ of the world's gross domestic product (A. A. Raheem \& Hinze, 2014). Despite the important economic benefits of the building sector, the building industry is concerned with a relatively high number of accidents and casualties. According to the survey from the ILO, 270 million workplace injuries are reported worldwide annually. The whole accidents impact millions of households by destroying the lives of around 2.2 million workers and affecting 1.6 million health of the population, resulting in a disquieting figure of 6,000 workplace health problems in one day. However, building firms across the globe are introducing protection, health and environmental management programmes to minimize accidents, eradicate disease and create a healthy working atmosphere for their workers (Choudhry, R. M., Fang, D., \& Rowlinson, 2008). In developing countries like Pakistan, construction operations in recent years have been steadily expanding with more than 3 million industry staff (PBS., 2018). In Pakistan, building workers make up $7.6 \%$ of the total work force, with building accidents and casualties responsible for about $17.3 \%$ of all fatal and non-fatal accidents. (PBS., 2018). Despite these troubling figures, almost no significant attempts have been made to improve the safety conditions of building workers in Pakistan (A. A. Raheem \& Hinze, 2012). Informal studies have shown not only that safety failure has contributed to a spike in injury, but also to delays, 
overruns in cost and low production. (Hafiz Zahoor Ahmad Khan \& Rafiq M. Choudhry, 2012) In Pakistan's building industry, health and safety provisions mainly are included in contract agreements but are not properly implemented because of employees' negligence and ignorance of their rights which lead to poor safety performance. In addition, reported statistics on building injury and mortality are not available in any credible manner. (Hafiz Zahoor Ahmad Khan \& Rafiq M. Choudhry, 2012). Alike the majority of the under developing countries, there are numerous hurdles and threats that Pakistani construction industry is facing to improve the implementation of safety regulations within the building industry.

\section{Literature Review}

The building sector in developing countries needs to introduce a safety, health and environmental protection mechanism to execute projects without harm and reduce threats to the workplace (Choudhry, R. M., Fang, D., \& Rowlinson, 2008). Main causes of injuries have been recognized as the unique nature of the building industry, human actions, hazardous working environments and inadequate safety management (Syed M. Ahmed, 2013).

Safety is an important concern for ensuring continuous work and protecting workers ' lives in all types of industries. Construction protection and health is a situation in which workers need a safe and healthy atmosphere for themselves and other individuals who are influenced by its practiced. A variety of factors have been identified that impact safety efficiency in the construction industry, including employee behaviour, the size of the construction firm, security policies, project planning, economic pressure, management training, and safety culture. Low safety awareness of top management, lack of preparedness, weak safety awareness of project managers and inability to input protection services and unsafe activities are the reasons impacting safety on building sites (Tam, Zeng, \& Deng, 2004) . There are three aspects of positive conduct: awareness, equipment on work, determination to act safely. (Marsh, Chessor, Craven, \& Roche, 1995). There have been multiple types of work casualties, ranging from mild incidents to fatal accidents, attributed to unsafe or inadequate safety procedures. The owner / developer / contractors and other site personnel are primarily responsible for construction safety. The progress of a project relies on the detailed preparation and On-site decisions on safety measures.

However, in Pakistan the safety performance of large and small contractor firms also differs significantly as most large companies in category C-A (contractor groups without financial limit) registered with the Pakistan Engineering Council have clear security policies and provide employees with certain standards of training and maintain safety staff at their job sites. Small companies, in comparison, do not have general safety on their agenda, so many building projects suffer from unsafe conditions and many injuries and accidents impact employees (Choudhry \& Zahoor, 2016). However, there is hardly regulation on safety in developing countries like Pakistan, and insufficient, ineffective or outdated regulation is in existence. Nonetheless, the laws and regulations on building safety cannot be applied because in Pakistan there is no worker health and safety control authority functioning in a capacity similar to that of OSHA in the United States (Choudhry, R. M., Fang, D., \& Rowlinson, 2008).

Subsequently training systems for workers are not available for certain work sites of the contractor; inductive training is not performed for new hires or staff; risks are not evaluated, and security meetings are not held. Furthermore, in isolated areas, there are also lack of readily available medical services, inadequate housing and poor sanitation.

As this is a global concern, both emerging and developed countries need to put a great deal of focus on preparation and the use of robust safety systems (Syed M. Ahmed, 2013). In addition, injuries and harm to employees, property, equipment and morale have adverse implications for the viability of the company and also for the competitiveness of the company (Lodi-Smith, Geise, Roberts, \& Robins, 2009). Consequently, such safety protocols and practises must be followed for worksite operations and awareness raising among staff, site managers and engineers for every construction project.

\subsection{Main Causes Of Poor Safety Practices In Construction Sites:}

Researchers studied the underlying causes of unsafe safety practises at the workplace, which eventually led to injuries at the construction site. According to (Ridley, 1986), dangerous actions or unsafe procedures are largely responsible for significant injuries. He stated that almost 99 per cent of fatal injuries occur as a result of either dangerous activities or unsafe procedures or both. According to Toole, (2002), there have been eight underlying factors of poor safety practises that are primarily responsible for all building injuries. These include a lack of proper preparation, inadequate safety compliance, failure to provide protective equipment, dangerous methods or handling, dangerous site 
conditions, inability to use the safety equipment given, and a bad attitude towards safety. According to human elements, inadequate control of the workplace, lack of use of personal protective equipment ( PPE) and dangerous equipment used in building operations were the common reasons behind the poor safety practises at work.

Thus according Paringga \& Aribowo, (2016), instruction and appropriate training are intended to prevent human errors which could lead to injuries and enable employees and labourers to carry out repeated tasks skilfully. According to (Tam et al., 2004), the causes of injuries include low safety knowledge among top admistrators, lack of appropriate instructions, and poor information flow lack of correct technical guidance, uncontrolled operation, unwillingness to input resources for safety, lack of certified skill labor, unsafe equipment, lack of first aid measures, lack of innovative technology, lack of rigorous enforcement of safety regulation, lack of teamwork spirits, lack of protection in material transportation and storage, shortage of safety management manual, lack of organizational commitment, lack of personal protective equipment (PPE).

\section{Objectives Of Study:}

The objectives of the study are:

1) To evaluate the safety performance at construction sites.

2) To identify weaknesses in existing workplace safety practises.

3) To recommend preventive measures to expand safety at building sites.

\section{Research Methodology}

In order to determine the performance level of each safety practice, the findings of questionnaire surveys were analyzed to evaluate the rank of all safety practices. The most neglected safety practises have been identified on the basis of this survey. For data validation and reliability analysis, a statistical package for social sciences (SPSS) has been used. Internal consistency of the questionnaire has been calculated by the Cronbach's coefficient alpha method.

\subsection{Questionnaire Design:}

A thorough literature was carried out which suggested that a variety of safety practices and factors exist affecting safety performance of construction sites. However, for this study, only 33 safety practices which have most influence on safety performance of construction projects was selected clustered into 10 main safety factors, were shortlisted through a comprehensive literature review as shown in table 1.

General information was questioned in the first section of the survey questionnaire, using multiple choice questions, such as age, job experience, education, and grouping of respondents into contractors, consultants, and clients. Throughout the second section, respondents were asked to rank protection activities on a five-point Likert scale of 1 (Strongly Disagree ) to 5 (Strongly Agree).

\subsection{Pilot Study}

The goal of the pilot study was to improve the structure, style and composition of the questions and the overall survey content. Therefore two-step pilot study was conducted to ensure that the questions are straightforward, ambiguities are excluded and that they are applicable to a particular group. In first phase, the questionnaire was sent to five academia and industry experts, and their positive comments were addressed. The modified questionnaire has again been shared with two contractors, consultants and consumers who have not been involved in the final survey. The feedback from these people led to the improvement and removal of inconsistencies and differences and the final questionnaire is created with their feedback.

Table 1. Safety Practices identified through literature review :

\begin{tabular}{lll}
\hline \multicolumn{1}{c}{$\begin{array}{l}\text { Safety Practices } \\
\text { A. Management's commitment to safety }\end{array}$} & \multicolumn{1}{c}{$\begin{array}{c}\text { References } \\
\text { (Shah \& Alotaibi, 2018) }\end{array}$} \\
\hline 1. Safety is the primary concern of upper \\
$\begin{array}{l}\text { management and not productivity } \\
\text { 2. There is no workplace burden and safety } \\
\text { is given preference over time. }\end{array}$ & $\begin{array}{l}\text { (Nadhim, Hon, Xia, Stewart, \& Fang, } \\
\text { 2016), (Gao, Chan, Utama, \& Zahoor, } \\
\text { 2016) }\end{array}$ \\
\hline
\end{tabular}


3. Upper management / safety officers carry (Feng, Teo, Ling, \& Low, 2014) out routine safety inspections.

4. Management is really serious about the

(A. A. Raheem \& Hinze, 2012) safety and health of those who work here.

5. Field Engineer, Supervisor and safety officer promote hazard reporting.

B. Workers' involvement

6. Safety laws and policies are strictly practised by staff.

7. Staff respond strongly to any violations of the safety rules by employees.

8. People here still work comfortably even though they're not being watched.

C. Safety in the contract documents

9. In any type of contract, contractor had been required to present the project's 'safety policy.'.

10. Before beginning each task, the contractor is expected to provide a 'safety plan.'

D. Safety rules/procedures and policies

11. Safety audits are routinely performed.

12. The first aid service is made accessible on-site.

E. Accident reporting and investigation mechanism

13. There is a written framework for accident reporting and investigation.

14. Accidents are usually reported/recorded

15. Investigations to determine causes of injuries are often carried out.

F. Safety training

16. New employees' training is mandatory.

17. The staff of subcontractors are also provided with safety training.

18. The organizational chart shows the names, roles and responsibilities for safety compliance on the site.

19. Safety banners and signboards are used in crucial locations for staff awareness, in English and Urdu.

G. Safety meetings

20. Safety is addressed at all progress and pre-construction gatherings.

(Awwad, El Souki, \& Jabbour, 2016)

(Adeeba A. Raheem \& Issa, 2016)

(Hafiz Zahoor Ahmad Khan \& Rafiq M. Choudhry, 2012)

(A. A. Raheem \& Hinze, 2014)

(Hafiz Zahoor Ahmad Khan \& Rafiq M. Choudhry, 2012)

(Adeeba A. Raheem \& Issa, 2016)

(A. A. Raheem \& Hinze, 2012)

(A. A. Raheem \& Hinze, 2012)

(El-Mashaleh, M., H., \& Rbabeh, 2010)

Chenet et al., 2013

(López Arquillos, Rubio Romero, \& Gibb, 2012)

(Jeyakanthan, J. and Ahamad, 2012)

(López Arquillos et al., 2012)

Geneva et al., 2012

(Rizwan U Farooqui \& Farrukh Arif, 2008)

(Gunawardana \& Jayawardane, 2003)

(Belel \& Muhmud, 2012)

(El-Mashaleh et al., 2010)

(Tam et al., 2004)

(El-Mashaleh et al., 2010)

(El-Mashaleh et al., 2010)

21. In safety discussions subcontractors also participate.

H. Use of personnel protection equipment (PPE)

(Belel \& Muhmud, 2012)

(Rizwan U Farooqui \& Farrukh Arif, 2008)

(Rizwan U Farooqui \& Farrukh Arif, 2008) issuance/ inspection / replacement scheme for the PPE

23. PPE is of high standard, used on site.

(Galappatti, Silva, Silva, \& De, 2013) 
24. Employees are expected to enter the workplace with hard hats on it.

25. Hearing protection and safety glasses are (Jackson et al., 2011) most often used when required.

26. At the height, workers often use safety belts and a protected lanyard.

\section{Safety practices}

27. Walkways / stairs not packed with litter and muddy spots washed up periodically.

28. Scrap is periodically extracted.

29. No material / equipment carelessly tossing or falling.

30. Sharp corners, including nails and metal bars, are coated / protected

\section{J. Quality of scaffolding and ladders}

31. Specifically built / connected scaffolds are utilized which are regularly checked.

32. Guardrails are mounted on working scaffold platforms to avoid falling.

33. High quality ladders are used at construction sites without faulty rungs.
(Vitharana, De Silva, \& De Silva, 2015)

(Somasundaraswaran, Brammananda, Akeel, \& Rajakumar, 2006)

(Hafiz Zahoor Ahmad Khan \& Rafiq M. Choudhry, 2012)

(Hafiz Zahoor Ahmad Khan \& Rafiq M.

Choudhry, 2012)

(Hafiz Zahoor Ahmad Khan \& Rafiq M.

Choudhry, 2012)

(Hafiz Zahoor Ahmad Khan \& Rafiq M.

Choudhry, 2012)

(Ahamed, Nafeel, Rishath, \&

Dissanayake, 2011)

(Abdul Hamid, Wan Yusuf, \& Singh,

2003)

(Hafiz Zahoor Ahmad Khan \& Rafiq M.

Choudhry, 2012)

(Jackson et al., 2011), (Rizwan U

Farooqui \& Farrukh Arif, 2008)

(Hu, Rahmandad, Smith-Jackson, \&

Winchester, 2011)

\subsection{Sample Size}

By year 2017-18, over 2737 construction companies in different groups have been registered with the Pakistan Engineering Council (PEC). in Sindh province. This statistic has been used as the population size. Therefore, the responses were assumed to be homogeneous and the $p$ value would be set to 0.5 . When these values are added to Equation 1, The appropriate sample size was determined to be 93 for a sampling error of $\pm 10 \%$.

$\mathrm{n}=[(\mathrm{N})(\mathrm{p})(1-\mathrm{p})] /[(\mathrm{N}-1)(\mathrm{B} / \mathrm{C}) 2+(\mathrm{p})(1-\mathrm{p})](1)$

Where:

$\mathrm{n}=$ Required sample size (notation commonly used $\mathrm{n}$ )

$\mathrm{N}=$ Population size i.e. 2737

$\mathrm{p}=$ Proportion of the population that is expected to choose one of the response categories (yes/no); $\mathrm{P}$ $=0.5$

$B=$ sampling error; $( \pm 10 \%$ or \pm 0.10$)$

$C=Z$ statistic associated with confidence level $(Z=1.96$ for $95 \%$ confidence level)

\subsubsection{Characteristics Of Respondents}

Three Hundred (300) questionnaire sets were distributed, as results a total of two hundred and ten (210) questionnaire sets were collected back. The response rate for the survey was $70 \%$ which is acceptable.

It can be observed in Fig. 1, the highest response came from the contractor it is $51.94 \%$, the response of the consultant was ranked as second, it was $25.97 \%$ and $22.09 \%$ percent to the client organizations.

Respondents of the building industry worked at various ranks such as executives $27.4 \%$, engineers $24.5 \%$, supervisors $19.6 \%$, employees $14.7 \%$ and the safety officials $13.8 \%$ and therefore Fig.2 shows education level of all respondents. 


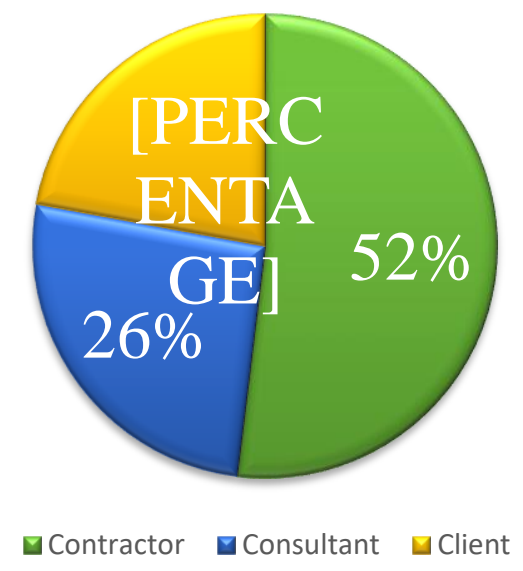

Figure 1 : Respondents based on categories

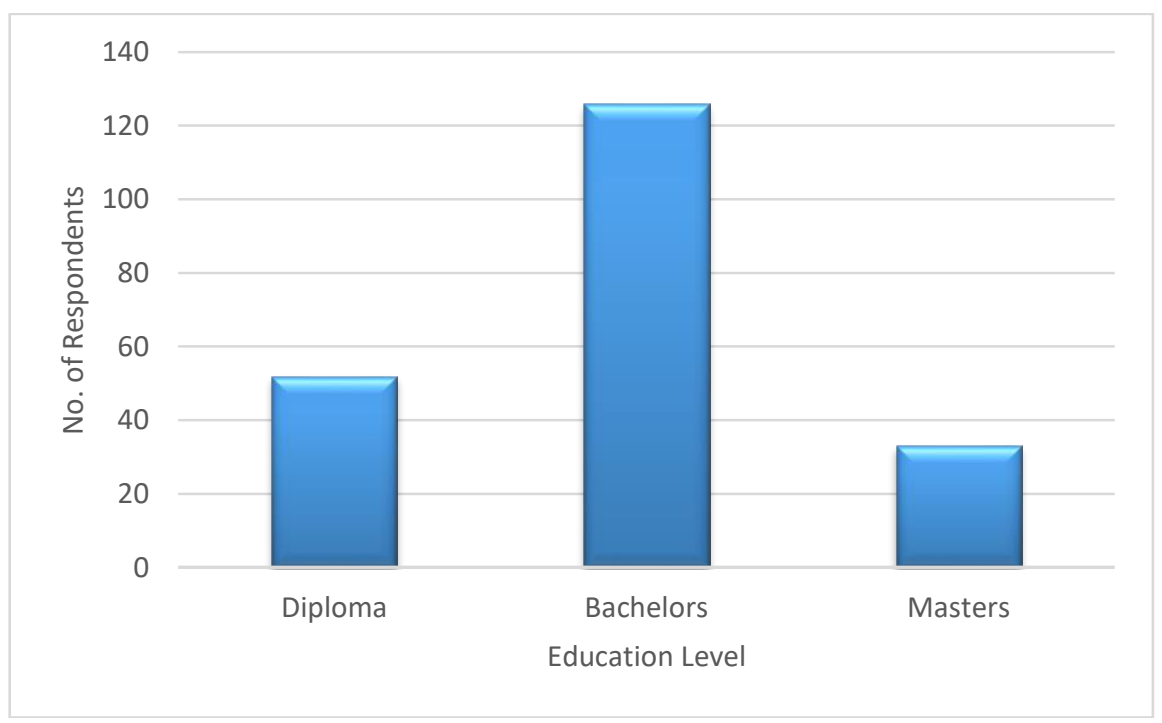

Figure 2 : Respondents Education Level

\subsubsection{Type Of Building Firms Participating In The Survey}

The survey included responses from 30 PEC registered construction firms operating in the Sindh Province. Respondents from the numerous organizations represented clients, consultants and contractors. The building firms involved in the survey are divided based on their PEC category in Table 2.

Table 2 : Size of companies based on PEC categories

\begin{tabular}{|c|c|c|}
\hline PEC category & Financial limit of each category & No. of companies \\
\hline C-A & No financial limit & 2 \\
\hline C-B & 2,000 Million & 3 \\
\hline C-1 & 1,000 Million & 5 \\
\hline C-2 & 500 Million & 9 \\
\hline C-3 & 250 Million & 7 \\
\hline C-4 & 100 Million & 4 \\
\hline C-5 & 30 Million & - \\
\hline C-6 & 15 Million & - \\
\hline Total & & 30 \\
\hline
\end{tabular}




\section{Data Analysis}

\subsection{Reliability Of The Data}

To obtain Cronbach's Alpha value, data collected from 210 valid questionnaire forms was analyzed using SPSS software. The Alpha of Cronbach is 0.816 , which means that the consistency is high, and the data obtained is valid, since the Alpha of Cronbach is greater than 0.7.

\section{Ranking Of Safety Practices}

SPSS was used to analyze the collected data. Mean and percentage values were determined to rate the performance of all safety practices (see Appendix-A). In the Sindh Province of Pakistan, mean safety performance value for the construction sector was estimated as 3.045 (60.914 per cent) preferably closer to 5 . The findings have revealed the most neglected safety practices that need extra consideration from all stakeholders of the building industry.

1) Labours do not work safely at workplaces when they are not being supervised.

2) Safety training sessions are not conducted for the employees of subcontractors.

3) Investigations are not carried out to identify the causes of accidents at worksites.

4) Accidents are not reported/recorded.

5) Workers are always careless when they throw or drop the material/equipment.

6) Walkways/staircases always littered with debris and wet spots do not clean up regularly.

7) Good quality ladders are not used on the worksite; usually, those ladders are used having defective rungs.

8) An organizational chart is not displayed on worksite showing names, positions and responsibilities for safety compliance.

9) Guardrails are not always placed on working scaffold platforms to prevent any fall.

10) PPE used on-site, is of inferior quality.

\section{Ranking Of Safety Factors}

All safety practices have been listed in 13 safety factors. Mean, and percentage values have been determined for all safety factors (Table 3 ) in order to rank the performance level of each safety factor. Results revealed the factor' Safety in the contract documents' has got the highest safety performance value of 3.416 (68.32), followed by the factor of 'Management's commitment to safety' 3.341 (66.82). The factor of 'Accident reporting and investigation mechanism' has got the lowest performance value of 2.791(55.82), it ensures that 'Accident reporting and investigation mechanism' is the most overlooked safety factor, it is accompanied by 'Workers' involvement' (58.04), 'Safety training' (58.54) and 'Safety practices' (58.74).

Table 3: Ranking of safety factors

\begin{tabular}{|c|c|c|c|c|}
\hline S. No & Safety factors & Mean & Percentage & Ranking \\
\hline 1. & Management's commitment to safety & 3.341 & 66.82 & 2 \\
\hline 2. & Workers' involvement & 2.902 & 5804 & 9 \\
\hline 3. & Safety in the contract documents & 3.416 & 68.32 & 1 \\
\hline 4. & Safety rules/procedures and policies & 3.104 & 62.08 & 3 \\
\hline 5. & $\begin{array}{c}\text { Accident reporting and investigation } \\
\text { mechanism }\end{array}$ & 2.791 & 55.82 & 10 \\
\hline 6. & Safety training & 2.927 & 58.54 & 8 \\
\hline 7. & Safety meetings & 2.979 & 59.58 & 6 \\
\hline 8. & $\begin{array}{l}\text { Use of personnel protection } \\
\text { equipment (PPE) }\end{array}$ & 3.091 & & 4 \\
\hline 9. & Safety practices & 2.937 & $\begin{array}{l}61.82 \\
58.74\end{array}$ & 7 \\
\hline
\end{tabular}




\section{0. \\ Quality of scaffolding and ladders}

Average safety performance
2.990

3.047
59.8

60.596

\section{Discussion}

For construction projects in Sindh Province, construction safety performance is estimated as 60.596 per cent (Table 3), preferably nearer to $100 \%$. This ensures that health standards in the construction industry need to be improved.

\subsection{Safety Practices}

The most neglected practices in the building sector are underlined as :

1. When Labours are not monitored, workers take unnecessary risks and lead to a high rate of accident.

2. Subcontractor workers are not provided with safety training, since workers can easily be injured or even killed without adequate training.

3. The inquiries are not undertaken in order to determine the reasons for occupational injuries as accidents are useful in detecting safety risks or preparation for safety and should be taken into account to minimize the risk of future injury.

4. There is no documentation or recording of incidents, but injury incidents and ill-health records may be used as a method for assessing risk to create future risk solutions better. Records also lead to avoidance and monitoring of unintended losses and injuries.

5. Employees are often reckless when they throw or drop the material/equipment, dropping instruments and equipment has an immense detrimental effect on production and, of course, most significantly, is the loss of life Also for recoverable conditions, it is devastating for the victims and families affected - it will lead to a loss of income and continuing medical costs.

\subsection{Safety Factors}

The ranking of safety factors showed that 'Accident reporting and investigation mechanism' is the most neglected safety factor, followed by 'Workers' involvement' 'Safety training' and 'Safety practices. The survey discovered that refresher safety training sessions are not conducted at all. Whereas on most sites, there is no organizational chart that shows safety duties, subcontractor employees do not receive safety training or not provided with safety equipment. However, Subcontractor participation in safety meetings is not encouraged. Progress meetings only focus on issues related to productivity when safety is not discussed. Sometimes workers do not comply with safety standards and procedures and tend to take unnecessary risks if they are not supervised. Moreover, Workers do not have a feeling of being comfortable wearing PPEs. Consequently, Training and media campaigns are necessary to educate workers on the significance of safety.

\section{Conclusion}

1. This paper examines the existing building safety literature and describes the construction safety defects. The results can be summarized as follows

2. The safety performance of construction in Sindh Province of Pakistan is estimated at $60.596 \%$.

3. The often ignored safety practices which require special care in order to increase safety performance are: Labour force does not operate safely in the workplace if it is not monitored, for subcontractors staff, safety awareness sessions are not held, Investigations are not performed to determine the causes of injuries at job places, Accidents are not reported/recorded, Workers are always careless when they throw or drop the material/equipment.

4. The factor 'Accident reporting and investigation mechanism' has the lowest safety performance value, i.e. $55.82 \%$. It is quite evident that contractors do not prioritize to record and maintain accident statistics, and only focus on productivity.

5. The second most overlooked safety factors are 'Workers' involvement' 'Safety training' and 'Safety practices.

6. Staff often refuse to follow safety guidelines and standards and continue to take unnecessary risks while they are not monitored. For a fact, employees do not feel comfortable using personnel protective equipment. 
7. Subcontractors are not allowed to engage in safety meetings, and development sessions do not have safety on their agendas. Stakeholders primarily concentrate on increasing efficiency and cost and resources savings while safety is the lowest on their agenda.

\section{Recommendations}

1. Safety should still be emphasized, no matter how fast and according to which budget limitations the building has to be completed.

2. Training, workshops, seminars, posters, banners are used to increase awareness of staff

3. Collaboration with international organizations working on workers ' OSH rights could take place in order to bring pressure on local authorities and governments.

4. The company's certification of ISO and collection process for data regarding OSH problems should be reviewed.

5. Safety training and awareness workshops may be held daily, and staff may be made aware of the necessity of using personal protective equipment. In addition, safety signs and posters with photographs illustrating the appropriate safety requirements and safety responsibilities will be posted at conspicuous positions on building sites.

6. The selection of contractors can be dependent on previous safety records. Besides, PEC can amend its registration requirements to ensure that all building companies have a safety officer.

\section{References}

Abdul Hamid, A. R., Wan Yusuf, W. Z., \& Singh, B. (2003). Hazards at Construction sites, Proceeding of the 5th Asia. Pacific Strutural Engineering and Construction Conference,. Johor, Bahru.

Ahamed, M., Nafeel, A., Rishath, A., \& Dissanayake, P. (2011). Site Safety of Sri Lankan Building Constrction Industry,. Proceedings of the International Conference on Structural Engineering, Construction and Management (ICSECM). Kandy, Sri Lanka.

Awwad, R., El Souki, O., \& Jabbour, M. (2016). Construction safety practices and challenges in a Middle Eastern developing country. Safety Science, 83, 1-11. https://doi.org/10.1016/j.ssci.2015.10.016

Belel, Z. A., \& Muhmud, H. (2012). Safety Culture of Nigerian Construction Workers- A Case Study of Yola,. International Journal of Scientific\& Engineering Research, 3(9).

Choudhry, R. M., Fang, D., \& Rowlinson, S. (2008). Challenging and enforcing safety management in developing countries: A strategy. International Journal of Construction Management, 8(1), 87101.

Choudhry, R. M., \& Zahoor, H. (2016). Strengths and weaknesses of safety practices to improve safety performance in construction projects in Pakistan. Journal of Professional Issues in Engineering Education and Practice, 142(4).

El-Mashaleh, M. S., M., A.-S. B., H., H. and K., \& Rbabeh, S. M. (2010). Safety managemant in the Jordian construction industry,. Jordan Journal of Civil Engineering, 4(1).

Feng, Y., Teo, E. A. L., Ling, F. Y. Y., \& Low, S. P. (2014). Exploring the interactive effects of safety investments, safety culture and project hazard on safety performance: An empirical analysis. International Journal of Project Management, 32(6), 932-943.

Galappatti, L. L., Silva, S. De, Silva, G. H. M. J., \& De, S. (2013). "Investigation on Methods to Improve Helath and Safety Practices in Construction Sites", Special Session on Structural Solid Mechanics, 4th. Interantional Conference on Structural Engineering and Construction Management,. Kandy, Sri Lanka.

Gao, R., Chan, A. P., Utama, W. P., \& Zahoor, H. (2016). Multilevel safety climate and safety performance in the construction industry: Development and validation of a top-down mechanism. ,. International Journal of Environmental Research and Public Health, 13(11).

Gunawardana, N. D., \& Jayawardane, A. K. W. (2003). The Training needs of Construction Workers in Sri Lanka. Proceedings of Annual Sessions of IESL. Oct. 2001.

Hafiz Zahoor Ahmad Khan, \& Rafiq M. Choudhry. (2012). The most neglected construction safety practices in Rawalpindi/Islamabad. CIB W099 International Conference "Modeling and Building Health and Safety," 312-322. Retrieved from https://www.researchgate.net/publication/262012361_The_most_neglected_construction_safety 
practices_in_Rawalpindilslamabad

Hu, K., Rahmandad, H., Smith-Jackson, T., \& Winchester, W. (2011). "Factors Influencing the Risk of Falls in the Construction Industry: A Revies of the Evidence." Journal of Construction Management and Economics, 29(4).

Jackson, T. S., Artis, S., Hunng, Y. H., Kim, H. N., Hughes, C., Kleiner, B., \& Nolden, A. (2011). "Safety Critical Incidents among Small Construction Contractors: A Prospective Case Study",. The Open Occupational Health \& Safety Journal, 3, 39-47.

Jeyakanthan, J. and Ahamad, Z. (2012). Causes and Effects of Accidents in Building Construction Industry in Sri Lanka",. Proceedins of the 2nd Annual Sessions of the Society of Structural Engineers-Sri Lanka.

Lodi-Smith, J., Geise, A. C., Roberts, B. W., \& Robins, R. W. (2009). Narrating Personality Change. Journal of Personality and Social Psychology, 96(3), 679-689. https://doi.org/10.1037/a0014611

López Arquillos, A., Rubio Romero, J. C., \& Gibb, A. (2012). Analysis of construction accidents in Spain, 2003-2008. Journal of Safety Research, 43(5-6), 381-388. https://doi.org/10.1016/j.jsr.2012.07.005

Marsh, H. W., Chessor, D., Craven, R., \& Roche, L. (1995). The Effects of Gifted and Talented Programs on Academic Self-Concept: The Big Fish Strikes Again. American Educational Research Journal, 32(2), 285-319. https://doi.org/10.3102/00028312032002285

Mohammed, Y. D., Shamsul, B. M. T., \& Bakri, M. I. (2017). Assessing Workers Safety Management Knowledge on Construction Site. International Journal of Engineering Research \& Science (IJOER), 3, 20-26.

Nadhim, E., Hon, C., Xia, B., Stewart, I., \& Fang, D. (2016). Falls from Height in the Construction Industry: A Critical Review of the Scientific Literature. International Journal of Environmental Research and Public Health, 13(7), 638. https://doi.org/10.3390/ijerph13070638

Paringga, A., \& Aribowo, E. (2016). PENGEMBANGAN SISTEM INFORMASI GEOGRAFIS PARIWISATA DAERAH ISTIMEWA YOGYAKARTA BERBASIS WEBSITE. JSTIE (Jurnal Sarjana Teknik Informatika) (E-Journal), 4(1), 38-48. https://doi.org/10.12928/JSTIE.V4I1.10741

PBS. (2018). Labour Force Statistics. Retrieved from Pakistan Bureau of Statistics website: http://goo.gl/ZHsbrX

Raheem, A. A., \& Hinze, J. (2012). Reasons for the poor implementation of worker safety in the construction industry of Pakistan: a contractor's prospective. In CIB W099 International Conference "Modeling and Building Health and Safety". Singapore.

Raheem, A. A., \& Hinze, J. W. (2014). The disparity between construction safety standards: A global analysis. Safety Science, 70, 276-287.

Raheem, Adeeba A., \& Issa, R. R. A. (2016). Safety implementation framework for Pakistani construction industry. Safety Science, 82, 301-314. https://doi.org/10.1016/j.ssci.2015.09.019

Ridley, C. R. (1986). Cross-Cultural Counseling in Theological Context. Journal of Psychology and Theology, 14(4), 288-297. https://doi.org/10.1177/009164718601400405

Rizwan U Farooqui, \& Farrukh Arif. (2008). Safety performance in construction industry of Pakistan. First International Conference on Construction In Developing Countries, Karachi, Pakistan, 2(2), 74-87. Retrieved from https://scholar.google.com/citations?user=7DMbGhEAAAAJ\&hl=en\#d=gs_md_cita$\mathrm{d} \& u=\% 2 F$ citations\%3Fview_op\%3Dview_citation\%26hl\%3Den\%26user\%3D7DMbGhEAAAAJ\% 26citation_for_view\%3D7DMbGhEAAAAJ\%3A9yKSN-GCB0IC\%26tzom\%3D-420

Shah, R. K., \& Alotaibi, M. (2018). A Study of Unethical Practices in the Construction Industry and Potential Preventive Measures. Journal of Advanced College of Engineering and Management, 3, 55. https://doi.org/10.3126/jacem.v3i0.18905

Somasundaraswaran, A. K., Brammananda, T., Akeel, J. A., \& Rajakumar, G. (2006). (2006), Evaluation of Safety Level at Construction Sites in Sri Lanka, Pro,. Proceedings of the Third Academic Sessions,. University of Ruhuna.

Syed M. Ahmed, P. . (2013). A Strategic Framework to Improve Construction Safety Practices in Pakistan. International Conference on Safety, Construction Engineering and Project Management (ICSCEPM 2013), ("Issues, Challenges and Opportunities in Developing Countries"), 9-17.

Tam, C. M., Zeng, S. X., \& Deng, Z. M. (2004). Identifying Elements of Poor Construction Safety Management in China,. Safety Science, 42(7), 569-586.

Toole, T. M. (2002). Construction Site Safety Roles. Journal of Construction Engineering and Management, 128(3), 203-210. https://doi.org/10.1061/(ASCE)0733-9364(2002)128:3(203)

Vitharana, V. H. P., De Silva, G. H. M. J. S., \& De Silva, S. (2015). Health hazards, risk and safety practices in construction sites - a review study. Engineer: Journal of the Institution of Engineers, 


\section{APPENDIX 1. RANKING OF SAFETY PRACTICES}

\begin{tabular}{|c|c|c|c|c|}
\hline & Mean & Percentage & Ranking \\
\hline & & \multicolumn{3}{|c|}{ 1. Management's commitment to safety } \\
\hline 1. & $\begin{array}{l}\text { Safety is the primary concern of upper } \\
\text { management and not productivity }\end{array}$ & 3.083333 & 61.666 & 13 \\
\hline 2. & $\begin{array}{l}\text { There is no work pressure on workers and } \\
\text { safety is given priority over time. }\end{array}$ & 3.416667 & 68.333 & 4 \\
\hline 3. & $\begin{array}{l}\text { Upper management / safety officers carry } \\
\text { out routine safety inspections. }\end{array}$ & 2.916667 & 59.333 & 21 \\
\hline 4. & $\begin{array}{l}\text { Management is really serious about the } \\
\text { safety and health of those who work here. }\end{array}$ & 3.583333 & 71.666 & 2 \\
\hline 5. & $\begin{array}{l}\text { Field Engineer, Supervisor and safety } \\
\text { officer promote hazard reporting. }\end{array}$ & 3.708333 & 74.166 & 1 \\
\hline \multicolumn{5}{|c|}{ 2. Workers' involvement } \\
\hline 6. & $\begin{array}{l}\text { Safety laws and policies are strictly } \\
\text { practised by staff. }\end{array}$ & 3.125 & 62.5 & 10 \\
\hline 7. & $\begin{array}{l}\text { Staff respond strongly to any violations of } \\
\text { the safety rules by employees. }\end{array}$ & 3.083333 & 61.466 & 14 \\
\hline 8. & $\begin{array}{l}\text { People here still work comfortably even } \\
\text { though they're not being watched. }\end{array}$ & 2.5 & 50 & 33 \\
\hline \multicolumn{5}{|c|}{ 3. Safety in the contract documents } \\
\hline 9. & $\begin{array}{l}\text { In any type of contract, contractor had } \\
\text { been required to present the project's } \\
\text { 'safety policy.'. }\end{array}$ & 3.333333 & 66.666 & 5 \\
\hline 10. & $\begin{array}{l}\text { Before beginning each task, the contractor } \\
\text { is expected to provide a 'safety plan.' }\end{array}$ & 3.5 & 70 & 3 \\
\hline \multicolumn{5}{|c|}{ 4. Safety rules/procedures and policies } \\
\hline 11. & Safety audits are routinely performed. & 2.958333 & 60.1 & 18 \\
\hline 12. & $\begin{array}{l}\text { The first aid service is made accessible } \\
\text { on-site. }\end{array}$ & 3.25 & 65 & 6 \\
\hline \multicolumn{5}{|c|}{ 5. Accident reporting and investigation mechanism } \\
\hline 13. & $\begin{array}{l}\text { There is a written framework for accident } \\
\text { reporting and investigation. }\end{array}$ & 2.916667 & 58.933 & 22 \\
\hline 14. & Accidents are usually reported/recorded & 2.75 & 55 & 30 \\
\hline 15. & $\begin{array}{l}\text { Investigations to determine causes of } \\
\text { injuries are often carried out. }\end{array}$ & 2.708333 & 54.166 & 31 \\
\hline \multicolumn{5}{|c|}{ 6. Safety training } \\
\hline 16. & New employees' training is mandatory. & 3.166667 & 63.333 & 8 \\
\hline 17. & $\begin{array}{l}\text { The staff of subcontractors are also } \\
\text { provided with safety training. }\end{array}$ & 2.708333 & 52.166 & 32 \\
\hline 18. & $\begin{array}{l}\text { The organizational chart shows the names, } \\
\text { roles and responsibilities for safety } \\
\text { compliance on the site. }\end{array}$ & 2.872 & 57.1 & 26 \\
\hline 19. & $\begin{array}{l}\text { Safety banners and signboards are used in } \\
\text { crucial locations for staff awareness, in } \\
\text { English and Urdu. }\end{array}$ & 2.958333 & 59.966 & 19 \\
\hline \multicolumn{5}{|c|}{ 7. Safety meetings } \\
\hline 20. & $\begin{array}{l}\text { Safety is addressed at all progress and pre- } \\
\text { construction gatherings. }\end{array}$ & 3.041667 & 60.833 & 16 \\
\hline 21. & $\begin{array}{l}\text { In safety discussions subcontractors also } \\
\text { participate. }\end{array}$ & 2.916667 & 58.533 & 23 \\
\hline
\end{tabular}

This work is licensed under a Creative Commons Attribution- ShareAlike 4.0 International License. 


\begin{tabular}{|c|c|c|c|c|}
\hline \multicolumn{5}{|c|}{ 8. Use of personnel protection equipment (PPE) } \\
\hline 22. & $\begin{array}{l}\text { The organization has an efficient issuance/ } \\
\text { inspection / replacement scheme for the } \\
\text { PPE }\end{array}$ & 3.083333 & 61.666 & 15 \\
\hline 23. & PPE is of high standard, used on site. & 2.916667 & 58.333 & 24 \\
\hline 24. & $\begin{array}{l}\text { Employees are expected to enter the } \\
\text { workplace with hard hats on it. }\end{array}$ & 3.25 & 64.2 & 7 \\
\hline 25. & $\begin{array}{l}\text { Hearing protection and safety glasses are } \\
\text { most often used when required. }\end{array}$ & 3.041667 & 60.233 & 17 \\
\hline 26. & $\begin{array}{l}\text { At the height, workers often use safety } \\
\text { belts and a protected lanyard. }\end{array}$ & 3.166667 & 63.133 & 9 \\
\hline \multicolumn{5}{|c|}{ 9.Safety practices } \\
\hline 27. & $\begin{array}{l}\text { Walkways / stairs not packed with litter } \\
\text { and muddy spots washed up periodically. }\end{array}$ & 2.833333 & 56.666 & 28 \\
\hline 28. & Scrap is periodically extracted. & 3.125 & 62.444 & 11 \\
\hline 29. & $\begin{array}{l}\text { No material / equipment carelessly tossing } \\
\text { or falling. }\end{array}$ & 2.833333 & 55.666 & 29 \\
\hline 30. & $\begin{array}{l}\text { Sharp corners, including nails and metal } \\
\text { bars, are coated / protected }\end{array}$ & 2.958333 & 59.566 & 20 \\
\hline \multicolumn{5}{|c|}{ 10. Quality of scaffolding and ladders } \\
\hline 31. & $\begin{array}{l}\text { Specifically built / connected scaffolds are } \\
\text { utilized which are regularly checked. }\end{array}$ & 3.125 & 62.3 & 12 \\
\hline 32. & $\begin{array}{l}\text { Guardrails are mounted on working } \\
\text { scaffold platforms to avoid falling. }\end{array}$ & 2.916667 & 58.133 & 25 \\
\hline \multirow[t]{2}{*}{33.} & $\begin{array}{l}\text { High quality ladders are used at } \\
\text { construction sites without faulty rungs. }\end{array}$ & 2.875 & 57.1 & 27 \\
\hline & Average safety performance & 3.045 & 60.914 & - \\
\hline
\end{tabular}

